\title{
EXPERIMENTAL VALIDATION OF RIVETING PROCESS FE SIMULATION
}

\author{
Wojciech Wronicz \\ Institute of Aviation, Warsaw, Poland \\ Wojciech.wronicz@ilot.edu.pl
}

\begin{abstract}
Rivets are critical areas in metal airframes from the fatigue point of view. Fatigue behaviour of riveted joints depends strongly on the residual stress system around the rivet holes. The both most convenient and most common method of determining these stresses is the Finite Element (FE) analyses. The validation of models used is necessary to ensure the reliability of results.

This paper presents the validation process of the riveting FE simulations for the universal and the countersunk rivets. At first, the material model of the rivets was validated with the use of the force-displacement curves of the press stamp obtained experimentally. Because of the displacement measurement method, it was necessary to take into account the flexibility of the stand. After that, good correlation between the numerical simulations and the experiment was obtained for both rivet types.

At the second stage, strains around driven heads measured with the use of strip gauge patterns were compared with the results of the FE simulations. Quite good correlation was obtained for the countersunk rivet. In the case of the universal rivet, the numerical results are significantly higher values than the measured ones. Differences in correlation of the experiments and FE simulations for the analysed rivet types probably result from material differences of the rivets.
\end{abstract}

Keywords: rivets, riveting process modelling, experimental validation

\section{INTRODUCTION}

Since the Aloha Airline accident in 1988, the fatigue characteristics of riveted joints has been subjected to numerous investigations and analyses. Fatigue is the most common reason of failure in aerospace structures and very often cracks 
initiate near fastener holes [1]. In addition to heightening the risk of catastrophic failure, fatigue behaviour strongly influences the service cost of an aircraft since it determines the airframe lifespan as well as types and frequency of inspections.

Fatigue life of riveted joints depends strongly on the rivet type and riveting technology used. For identical specimens and loads, the number of cycles to failure can differ significantly [2] - [4]. Residual stresses after riveting play a crucial role in fatigue cracks nucleation and growth [5], [6]. Local maximum and minimum peak stresses at critical locations are used to estimate the fatigue life of riveted joints by both numerical analyses and a number of semi-empirical approaches [5]-[7]. In joined elements, the riveting process induces a complex stress state that analytical methods cannot properly predict. Numerical methods, especially Finite Element (FE) calculations, enable researchers to determine the stress distribution in the entire joint, also at the faying surface, where cracks usually nucleate. This location is practically inaccessible to experimental methods. It is characteristic of the FE analysis that input data (e.g. material models) can strongly influence the results, possibly leading to obtaining unrealistic values. In order to ensure that the model accurately represents the reality, its validation is necessary.

This paper presents the validation process of the riveting FE simulations. Two types of rivets were analysed, i.e. the universal rivet according to the MS20470 standard and the countersunk rivet according to the NAS1097 standard. Rivets were made of 2117-T4 alloy with diameter equal to $4 \mathrm{~mm}$. Sheets made of 2024-T3 alloy with thickness equal to $1.5 \mathrm{~mm}$ were selected. At first, force-displacement curves of the press punch obtained in the experiments and calculations were compared. In the next step, validations concerns strains near a driven head recorded by strain gauges and determined in calculations.

\section{FINITE ELEMENT MODELS}

The models of joints with two sheets and one rivet were prepared for the riveting process simulation based on previous works [8] - [10]. Four nodes linear elements for axisymmetric analysis were used. Each model consisted of three deformable contact bodies (a rivet and two sheets) and three rigid contact bodies (a hold-on, a punch and a support under the bottom sheet). The radius of sheets was equal to $30 \mathrm{~mm}$. The hold-on and the support were fixed while the punch was moving vertically forming a driven head until the force reached the assumed value, whereupon it was released. The central parts of the models are shown in Fig.1. Each model consisted of about $2500-3000$ elements. 

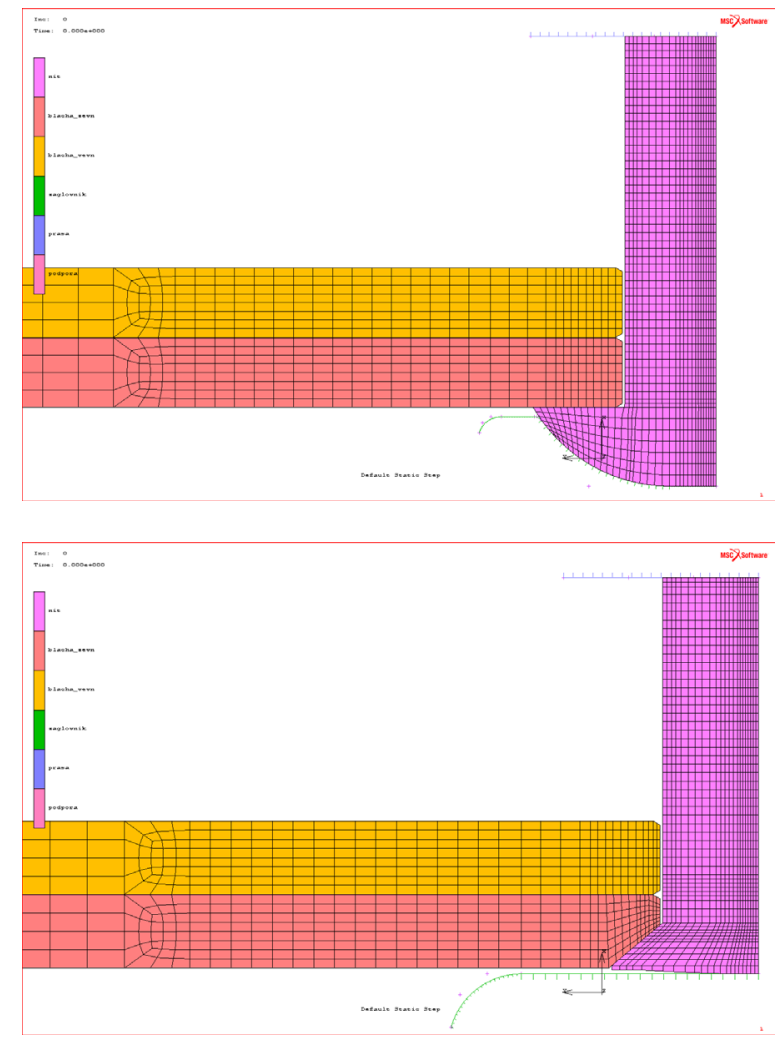

Figure 1. Central part of the FE models of joints

The quasi-static simulations of riveting were performed with the use of the implicit nonlinear algorithm (MSC Marc). The elasto-plastic material behaviour as well as contact phenomena were taken into account. The values of friction coefficients were assumed based on [11] and in the case of kinematic friction were equal to 0.34 for aluminium pairs and 0.15 for steel-aluminium interactions. In the case of static friction, coefficients values were 1.24 times higher. Material models are presented in Fig. 2. Model of the 2024-T3 alloy (sheet) was developed based on the material test, while in the case of the 2117-T4 alloy (rivet), the model was taken from [11].

\section{FORCE-DISPLACEMENT CURVES}

In order to validate the 2117-T4 alloy (rivet) material model, tests of squeezing rivets for both analysed types were performed on the MTS 312/68 testing machine. Each rivet was inserted into a hole in a one sheet to prevent it from rotating and squeezed with force equal to $36 \mathrm{kN}$. The test was repeated three times for both rivet types. The controller of the testing machine recorded squeezing forces 
and punch displacements. The FE models described above were modified to represent these tests. Figure 3 shows the experiment and the modified FE model of the universal rivet.

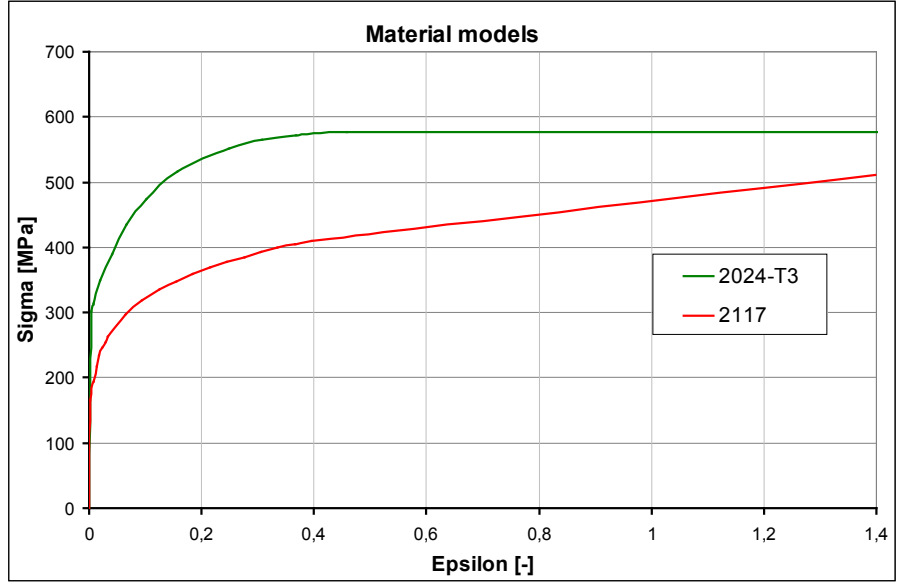

Figure 2. Material models

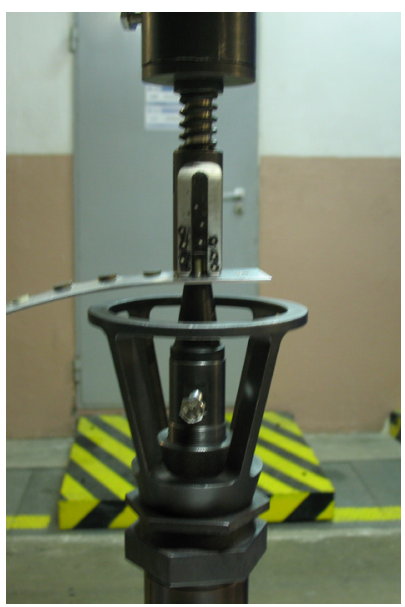

a)

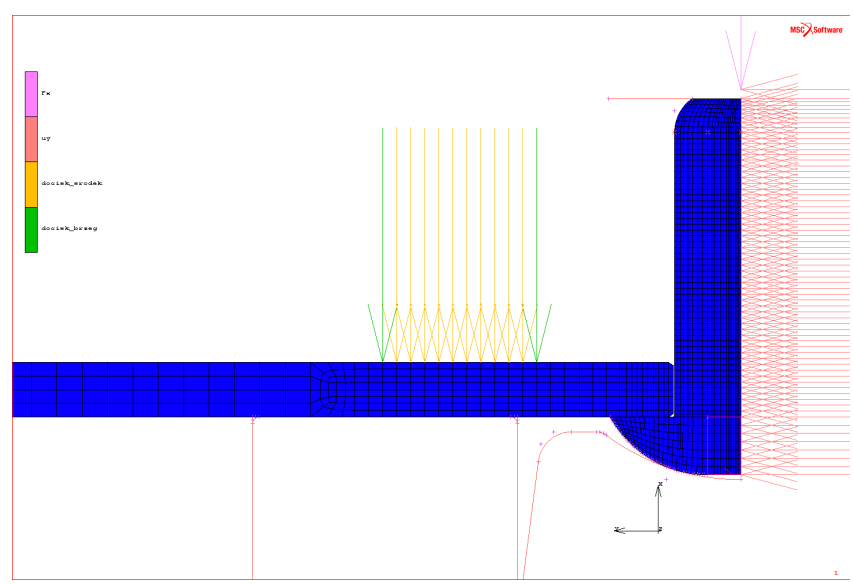

b)

Figure 3. Squeezing rivets, a) experiment, b) FE model

The displacements were measured by the testing machine controller and include also translations resulting from the flexibility and clearances of elements mounted into the testing machine. A piece of steal was squeezed in the stand to measure these additional displacements (Figure 4). The obtained 
force-displacement curve was interpolated by a polynomial and used for making a correction of the force-displacements curves obtained for rivet squeezing (for each point, the displacement measured during squeezing the steel plate was subtracted from the displacements measured during squeezing the rivet with a particular force value).

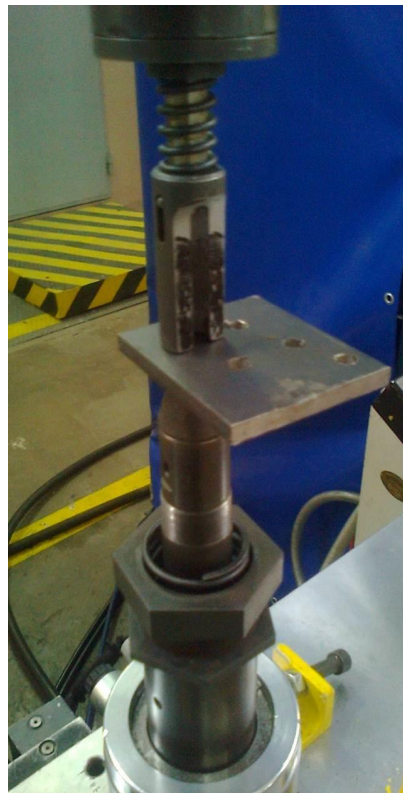

a)

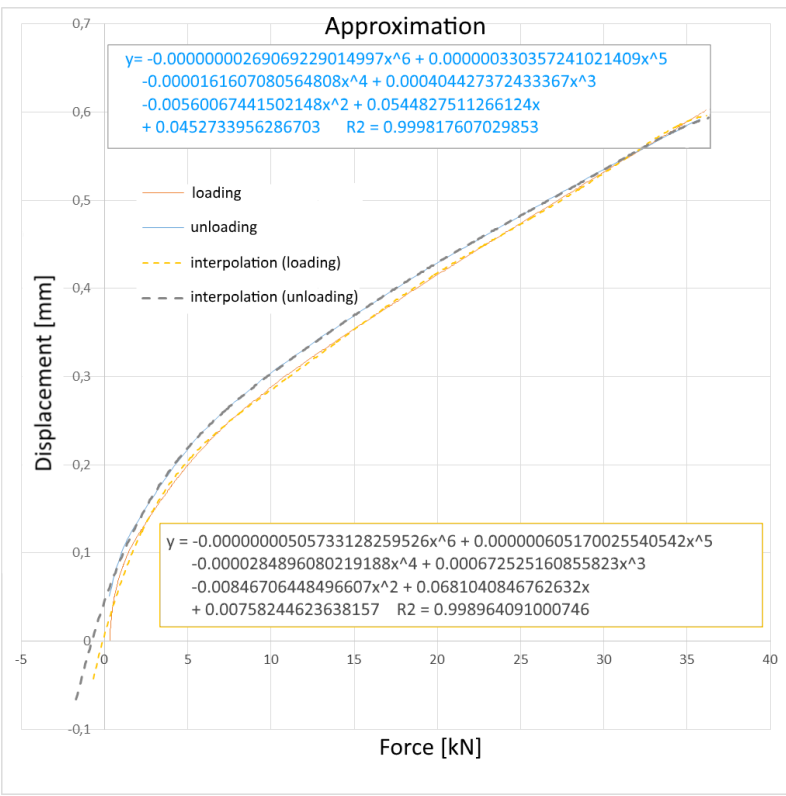

b)

Figure 4. Measurement of stand flexibility, a) experiment, b) obtained curves

Figure 5 presents comparison of force displacements curves obtained experimentally and through the FE calculations for both types of rivets. In the case of the universal rivet (Fig. 5a), the curve without correction was also presented. Experimental curves for three specimens were practically identical for both cases. Flexibility and clearances of the test stand caused distinct additional displacements recorded by the controller of the testing machine. After the correction described above, a good agreement between experiments and numerical analyses was obtained. 


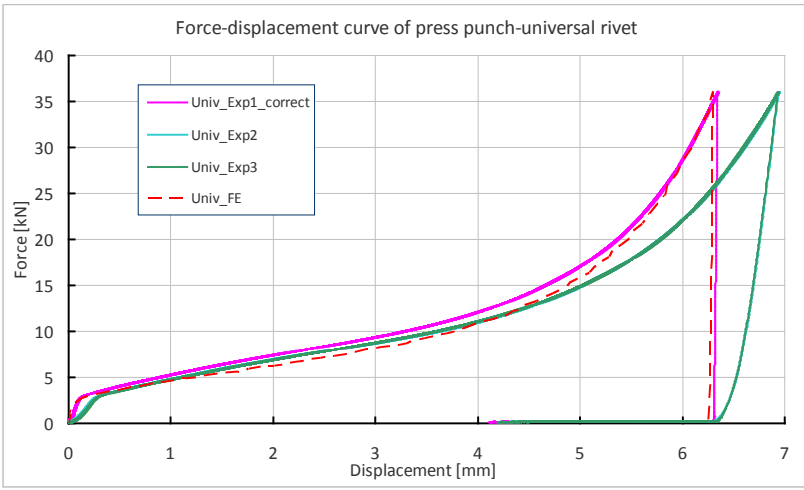

a)

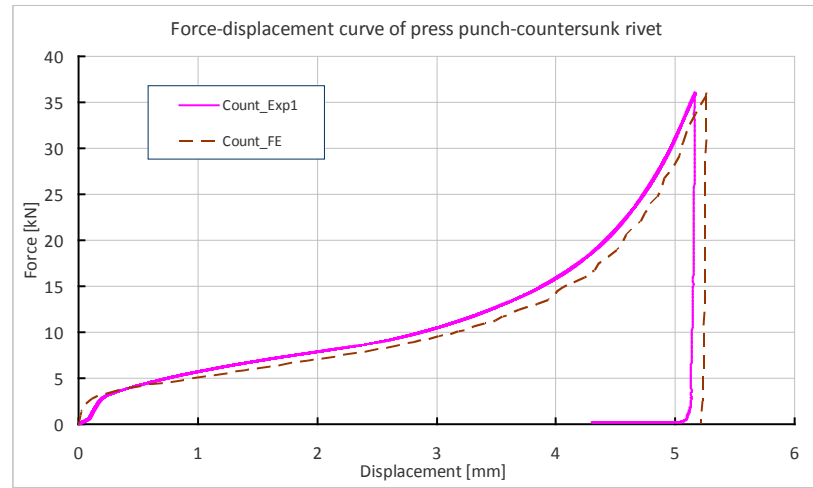

b)

Figure 5. Force displacements curves obtained experimentally and in FE calculations, a) universal rivet, b) countersunk rivet

\section{STRAIN DISTRIBUTION NEAR DRIVEN HEAD}

The next step in the models' validation involved comparing the strain distribution around the rivets' driven heads. The results of numerical calculations were compared against the data obtained during the strain gauge measurements [10]. Each specimen consisted of two bare sheets (2024-T3, $\mathrm{t}=1.6 \mathrm{~mm})$ and six rivets (2117T4, $\phi 4 \mathrm{~mm}$, universal or countersunk head). Around the central rivet, the Vishay strip gauges patterns type 020MT and $020 \mathrm{PF}$ were applied onto the driven head side to measure radial and tangential strains respectively. Figure 6 presents the specimens geometry and arrangement of strain-gauges around the central rivet. 

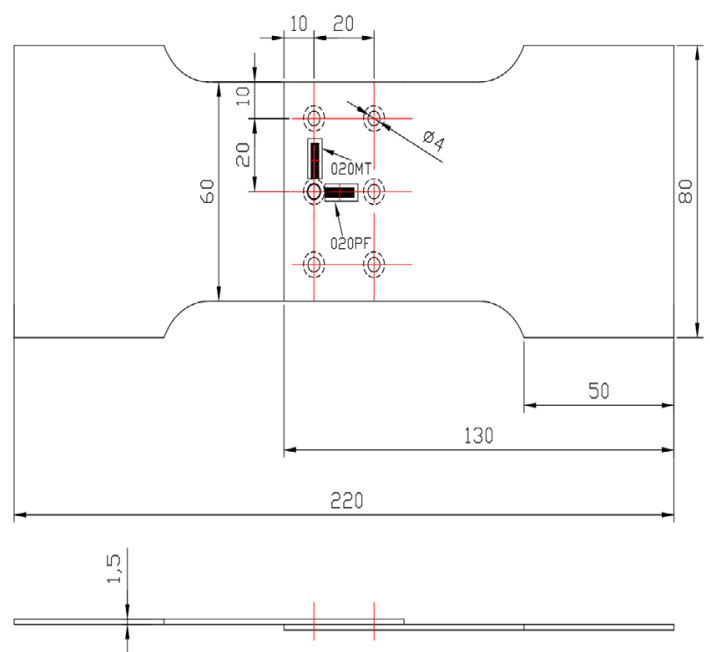

a)

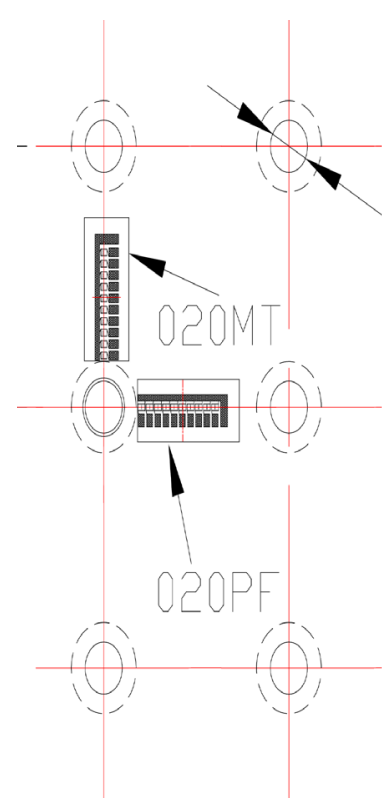

b)

Figure 6. Specimen configuration, a) geometry, b) strain gauges arrangement

Riveting was performed with a force controlled by the testing machine. For all rivets, the driven head diameter was about 1.7 times greater than the rivet shank diameter. The squeezing force was equal to $25 \mathrm{kN}$ and $24.5 \mathrm{kN}$ for the universal rivet and the countersunk rivet, respectively. At first, all rivets except the central one were successively squeezed, then during the last riveting, strains around the central hole were recorded. Measurements were performed on five specimens for each of the rivet type.

The recorded strains were compared against the results of the FE simulations. Due to axisymmetric analysis, each of the FE model represents a joint with circular sheets and a single rivet. Previous analysis shows that such simplification is appropriate [8]. Figures 7-8 presents strain distributions around driven heads for both rivet types determined during the measurements and the FE simulations. Experimental curves were designated with a specimen number. 


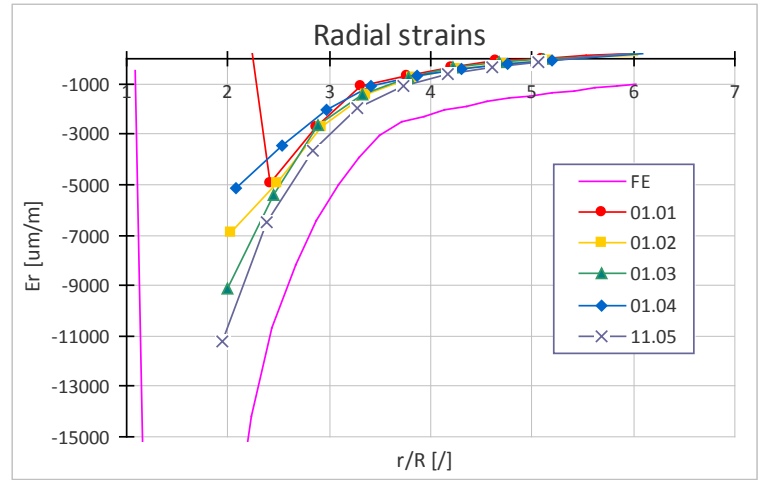

a)

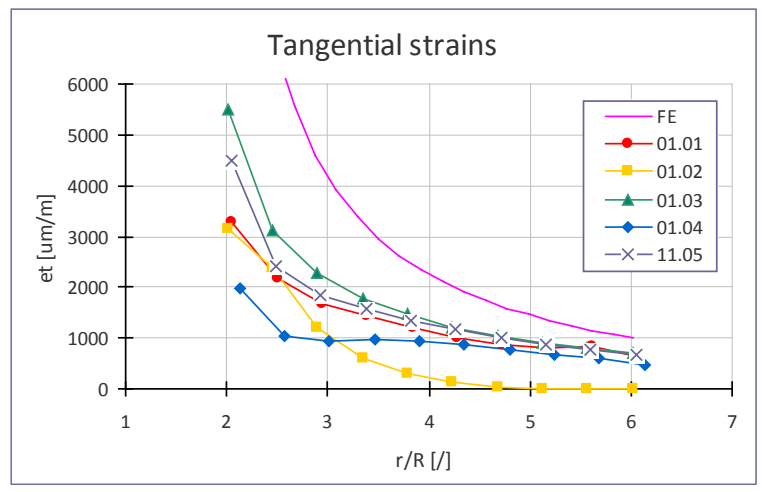

b)

Figure 7. Strain distribution around driven head for universal rivet a) radial, b) tangential, $r$-distance from rivet axis, $R$-river shank radius

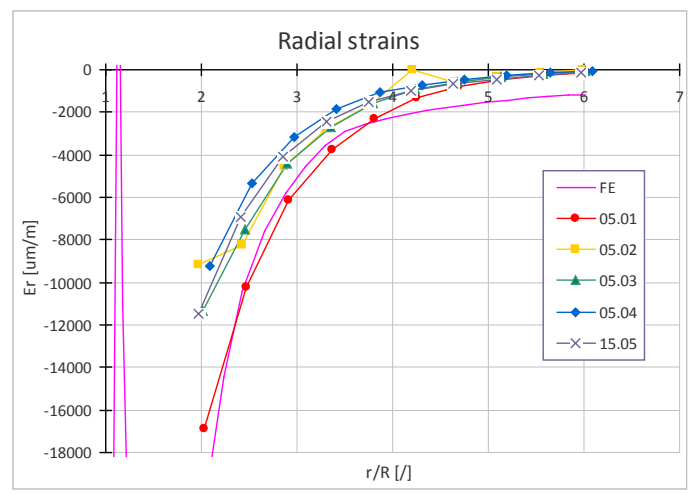

a) 


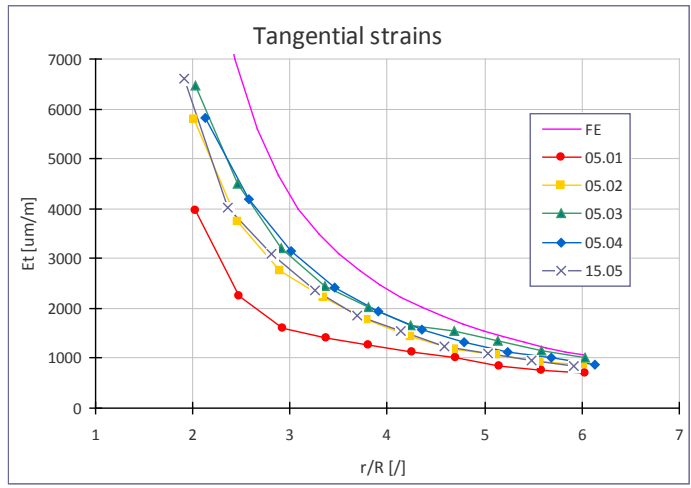

b)

Figure 8. Strain distribution around driven head for countersunk rivet a) radial, b) tangential, $r$-distance from rivet axis, $R$-river shank radius

In the case of the countersunk rivet, quite good correlations were obtained, especially for radial strains. Results of numerical simulation for the universal rivet were substantially higher than measured values. The main difference between the analysed FE models was the geometry. According to the experiment, in the FE simulations the squeezing force value in the case of the universal rivet was slightly higher than for the countersunk rivet. The sheets used in the experiment were the same for both cases. Rivets were made of the nominally identical alloy but were provided by various suppliers. Slight differences in material properties of used rivets probably is the reason of various level of correlation between simulation and experiment for analysed rivet types.

\section{CONCLUSIONS}

The paper presented the validation process of the riveting FE simulations. At first, the material model of rivet was validated with the use of the force-displacement curves of the press stamp. Because of the displacement measurement method, it was necessary to take into account the flexibility of the stand. The translations resulting from flexibility and clearances of the stand elements were measured and subtracted from the displacements measured during squeezing of the rivets. The magnitude of these corrections was found to be significant. After that, good correlation between the numerical simulations and the experiment was obtained for both rivet types.

At the second stage, strains around driven heads measured with the use of strip gauge patterns were compared with the results of the FE simulations. Quite good correlation was obtained for the countersunk rivet. In the case of the universal rivet, numerical results are significantly higher than measured values. Various levels of correlation of the experiments and FE simulations for the analysed rivet 
types probably result from material differences of the rivets. The presented study confirms that material characteristics are crucial in the case of FE simulations and a good correlation of calculation and experiment with respect to displacements do not ensures that numerically determined stress distribution will be correct.

\section{ACKNOWLEDGEMENT}

The researches were financed from the subsidy granted by the Polish Ministry of Science and Higher Education for statutory activities of the Institute of Aviation, Warsaw, Poland.

\section{REFERENCES}

[1] S. J. Findlay and N. D. Harrison, 'Why aircraft fail', Mater. Today, vol. 5, no. 11, pp. 18-25, Nov. 2002.

[2] R. P. G. Müller and L. J. Hart-Smith, 'Making fuselage riveted lap splices with 200-year crack-free-lives', in Fatigue in New and Aging Aircraft, Edinburgh, Scotland, 1997, pp. 18-20.

[3] M. Skorupa, A. Skorupa, T. Machniewicz, and A. Korbel, 'Effect of production variables on the fatigue behaviour of riveted lap joints', Int. J. Fatigue, vol. 32, no. 7, pp. 996-1003, Jul. 2010.

[4] A. Lipski, 'The Influence of The Degree of the Rivet Hole Sizing on the Fatigue Life', Fatigue Aircr. Struct., vol. 2012, no. 4, pp. 64-69, 2012.

[5] R. P. G. Müller, 'An experimental and analytical investigation on the fatigue behaviour of fuselage riveted lap joints', Delft University of Technology, Delft, 1995.

[6] A. Skorupa and M. Skorupa, Riveted Lap Joints in Aircraft Fuselage: Design, Analysis and Properties, 2012th ed. Dordrecht ; New York: Springer, 2012.

[7] J. J. Homan and A. A. Jongebreur, 'Calculation method for Predicting the Fatigue Life of Riveted Joints', in Durability and structural integrity of airframes, Stockholm, Sweden, 1993, vol. 1, pp. 175-190.

[8] W. Wronicz and J. Kaniowski, 'Experimental and Numerical Study of Strain Progress During and After Riveting Process for Brazier Rivet and Rivet with Compensator - Squeezing Force and Rivet Type Effect', Fatigue Aircr. Struct., vol. 2011, no. 3, pp. 166-190, 2011.

[9] W. Wronicz, 'Comparison of Residual Stress State on Sheets Faying Surface after Standard and NACA Riveting-Numerical Approach', Fatigue Aircr. Struct., vol. 2016, no. 8, pp. 116-126, 2016.

[10]W. Wronicz, J. Kaniowski, M. Malicki, P. Kucio, and R. Klewicki, 'Experimental and numerical study of NACA and conventional riveting procedure', Fatigue Aircr. Struct., vol. 2017, no. 9, pp. 157-170, 2017.

[11]J. Fárek, 'FE-Modelling Methodology of Riveted Joints', Czech Aerosp. Proc. J. Czech Aerosp. Res., vol. 2010, no. 3, pp. 12-16, 2010. 